\title{
Thermal Rating of Overhead Insulation-Covered Conductors in the Steady-State Regime
}

\author{
Stanislav Girshin, Vladimir Goryunov, Evgenii Kuznetsov, Elena Petrova, Anton Bubenchikov, Dmitrii Batulko \\ Omsk State Technical University, Energy Department, 644050 pr. Mira 11, Omsk, Russian Federation
}

\begin{abstract}
One can offer based on the solution of the heat equation and the heat balance equation a mathematical model of steady thermal regime of the conductor, which allows to determine the temperature of bare and insulationcovered conductors of overhead power lines, considering weather conditions, as well as to perform the calculation of electricity losses with conductors temperature. The expressions are for the gradient of temperature distribution in the current-carrying conductor, as well as conductor insulation with and without dielectric losses. The accuracy of the created model is checked when compared with the methods of CIGRE, IEEE and the Finite Element Method. High precision of matching results is achieved.
\end{abstract}

\section{Introduction}

Currently, there is a need to increase the capacity of transmission lines due to the accelerated growth of consumption power. One way to increase the ampacity through the transmission line is a reliable determination of the temperature of the wires in real time [1-6]. The calculation of the conductors temperature is possible with integrating operating and weather factors [7-9]. Along with the increase in load current the task is to reduce the losses of energy in electric networks. The loss of electricity is reduced with introducing measures to reduce losses. When selecting actions one must assume the network elements temperature. For example, when installing capacitor banks the energy loss is not only due to the actual reduction of the transmitted reactive power, but also by reducing the resistance. It reduces losses also to the transfer of active power, and not just reactive. Calculation excluding temperature will not consider these additional factors.

Paper considers the mathematical model of steadystate mode of insulation-covered conductor on the basis of the heat balance equation. The model allows to determine the temperature and the active power losses in the conductors of overhead lines. For creation of the model have been defined temperature gradient of conductor, the temperature changes in the conductor insulation and influence of dialectical losses on thermal mode. A positive feature of the mathematical model is a form of analytical equations obtained. It simplifies the implementation of the computer model and analysis results. The accuracy of equations is confirmed with good matching with the results of determining the temperature methods of IEEE [8], CIGRE [9] and the Finite Element Method (FEM) [10]. The practical value of the model is the ability to analyze both bare and insulation-covered conductors of overhead lines.

\section{Mathematical model of steady-state thermal rating}

Calculation of the temperature on the surface of the conductor $\Theta$ sur is performed on the basis of the heat balance equation. At steady-state the heat balance of insulated and bare overhead line conductor is given by equation (1)

$$
\begin{aligned}
\Delta p^{\prime}\left(1+\alpha \Theta_{\text {sur }}\right)= & d_{c}\left[\pi \alpha_{c}\left(\Theta_{\text {sur }}-\Theta_{\text {amb }}\right)\right. \\
& \left.+\pi \varepsilon C_{0}\left(T_{\text {sur }}^{4}-T_{a}^{4}\right)-A_{s} q_{s}\right]
\end{aligned}
$$

where $\alpha$ is a temperature coefficient of resistance; $d_{c}$ is outer diameter of the conductor; $\alpha_{c}$ is a coefficient of heat transfer with convection; $\Theta_{s u r}$ is temperature of the outer surface of the conductor $\left({ }^{\circ} \mathrm{C}\right) ; \Theta_{a m b}$ is ambient temperature $\left({ }^{\circ} \mathrm{C}\right) ; T_{a m b}$ is ambient temperature $(\mathrm{K}) ; T_{\text {sur }}$ is the temperature of the outer surface of the insulation $(\mathrm{K})$; $\varepsilon$ is the emissivity of the surface of the conductor; $A_{s}$ is the absorption capacity of the surface for solar radiation; $C_{0}$ is radiation coefficient of blackbody; $q_{s}$ is flux density of solar radiation on the conductor; $\Delta p_{0}^{\prime}$ is active power losses in the conductor per length unit at $\Theta_{s u r}=0^{\circ} \mathrm{C}$.

The values of $q_{s}, \Delta p^{\prime}{ }_{0}, \Theta_{\text {sur }}$ will be in equations (2-4):

$$
\begin{aligned}
q_{s} & =k_{s h} q_{s . d i r} \sin \varphi_{s}+\pi q_{s . d i f} \\
\Delta p_{0}^{\prime} & =\frac{I^{2} r_{0}}{1-\alpha I^{2} r_{0} S_{i n s}} \\
\Theta_{s u r} & =-\Delta p_{0} S_{i n s}+\Theta_{c}\left(1-\alpha \Delta p_{0} S_{\text {ins }}\right)
\end{aligned}
$$


where $q_{\text {s.dir }}$ is flux of direct solar radiation on the surface perpendicular to the sun's rays; $q_{\text {s.dif }}$ is flux density of diffuse solar radiation, averaged over all directions; $k_{s h}$ is reduction factor, which takes into account the shaded portion of the conductor (shading coefficient); $\varphi_{s}$ is the angle between the axis of the conductor and the direction of the sun's rays; $I$ is current in the conductor; $r_{0}$ is the pursuit of resistance at $0{ }^{\circ} \mathrm{C} ; \Delta p_{0}$ is heat (active power losses), calculated from the resistance, defined at temperature of $0{ }^{\circ} \mathrm{C} ; \Theta_{c}$ is conductor temperature; $S_{\text {ins }}$ is thermal insulation resistance per length unit, defined by equation (5).

$$
S_{i n s}=\frac{\ln \left(r_{2} / r_{1}\right)}{2 \pi \lambda_{i n s}}
$$

where $\lambda_{\text {ins }}$ is the thermal conductivity of the insulation; $r_{2}$ is the conductor outer radius; $r_{l}$ is the radius of the conductor without insulation.

The dependence of heat (active losses) in the overhead line conductor from the conductor temperature $\Theta_{c}$ as shown in equation (6)

$$
\Delta p=\Delta p_{0}\left(1+\alpha \Theta_{c}\right)
$$

The conductor temperature was determined by equation (7):

$$
\Theta_{c}=\frac{\Theta_{s u r}+\Delta p_{0} S_{i n s}}{1-\alpha \Delta p_{0} S_{i n s}}
$$

Equation (4) is obtained by solving the heat equation in partial derivatives.

The equations (1-7) are a mathematical model of steady-state thermal regime of overhead insulationcovered conductor

\section{The temperature gradient in the conductor}

\subsection{In the bare overhead conductor}

One considers a cylindrical conductor of infinite length of diameter $d_{l}$. One assumes that the temperature in all points of the same surface of the conductor and the bulk density of the heat release is $q_{v}=$ const. Under these conditions, the conductor temperature $\Theta$ is a function of distance from the conductor center $r$, and the heat equation in the steady-state, and its solution have the form as shown in equations (8), (9):

$$
\begin{gathered}
\frac{d^{2} \Theta}{d r^{2}}+\frac{1}{r} \frac{d \Theta}{d r}+\frac{q_{v}}{\lambda}=0 \\
\Theta(r)=\Theta_{\text {center }}-\frac{q_{v} r^{2}}{4 \lambda}
\end{gathered}
$$

where $q_{v}$ is volume density of heat; $\lambda$ is a coefficient of thermal conductivity, $\Theta_{\text {center }}$ is the temperature in the conductor center.
In accordance with equation (9) temperature change from the center to the surface of the conductor and the average temperature gradient are shown in equations (10), (11)

$$
\begin{gathered}
\Delta \Theta=\Theta_{\text {center }}-\Theta_{r}=\frac{q_{v} r_{1}^{2}}{4 \lambda} \\
\left(\frac{d \Theta}{d r}\right)_{a v}=\frac{\Delta \Theta}{r_{1}}=\frac{q_{v} r_{1}}{4 \lambda}
\end{gathered}
$$

\subsection{In the overhead insulation-covered conductor without dielectric losses}

If there is no dielectric losses in the insulation the heat conduction equation to insulate has the form as shown in equation (12)

$$
\frac{d^{2} \Theta}{d r^{2}}+\frac{1}{r} \frac{d \Theta}{d r}=0
$$

As a result of integration of equation (5) obtain equation (13) [11]:

$$
\Theta=C_{1} \ln r+C_{2}
$$

where $C_{1}, C_{2}$ are integration constants determined from boundary conditions.

The final solution of equation (13) is presented in equation (14)

$$
\Theta=\Theta_{\text {sur }}+\frac{q_{v} r_{1}^{2}}{2 \lambda_{\text {ins }}} \ln \frac{r_{2}}{r}
$$

If you set the temperature on the internal surface of the insulation, about equal to the temperature in the conductor center $\Theta_{\text {center }}$ then is obtained equation (15)

$$
\Theta \approx \Theta_{\text {center }}+\frac{q_{v} r_{1}^{2}}{2 \lambda_{\text {ins }}} \ln \frac{r_{1}}{r}
$$

The temperature change in the insulation is presented by equation (16)

$$
\Delta \Theta_{i n s}=\Theta_{\text {center }}-\Theta_{\text {sur }}=\frac{q_{v} r_{1}^{2}}{2 \lambda_{\text {ins }}} \ln \frac{r_{2}}{r_{1}}
$$

\subsection{In the overhead insulation-covered conductor with accounting of dielectric losses}

If there are dielectric losses of insulation the heat equation has the form as shown in equation (17)

$$
\frac{d^{2} \Theta}{d r^{2}}+\frac{1}{r} \frac{d \Theta}{d r}+\frac{q_{v, \text { ins }}}{\lambda_{\text {ins }}}=0
$$

where $q_{v, \text { ins }}$ is the bulk density of heat insulation.

The value of $q_{v \text {,ins }}$, is proportional to the square of the electric field. If we consider the radial electric field of a single conductor, the tension is inversely proportional to $r$ [12] and can be written by equation (18) 


$$
q_{v, \text { ins }}=\frac{K_{1}}{r^{2}}
$$

Equation (17) takes the form as shown in equation (19)

$$
\frac{d^{2} \Theta}{d r^{2}}+\frac{1}{r} \frac{d \Theta}{d r}+\frac{K_{1}}{r^{2} \lambda_{i n s}}=0
$$

The general solution is defined by the equation (20):

$$
\Theta=C_{1} \ln r-\frac{K_{1} \ln ^{2} r}{2 \lambda_{\text {ins }}}+C_{2}
$$

where $C_{l}, C_{2}$ are integration constants, $K_{l}$ is the coefficient of proportionality.

The final solution and the temperature change in the insulation take the form as shown in equations (21), (22)

$$
\begin{aligned}
& \Theta=\Theta_{\text {sur }}+\frac{q_{v} r_{1}^{2}-2 K_{1} \ln r_{1}}{2 \lambda_{\text {ins }}} \ln \frac{r_{2}}{r}+\frac{K_{1}}{2 \lambda_{\text {ins }}}\left(\ln ^{2} r_{2}-\ln ^{2} r\right) \\
& \Delta \Theta_{i n s}=\frac{q_{v} r_{1}^{2}-2 K_{1} \ln r_{1}}{2 \lambda_{i n s}} \ln \frac{r_{2}}{r_{1}}+\frac{K_{1}}{2 \lambda_{i n s}}\left(\ln ^{2} r_{2}-\ln ^{2} r_{1}\right)
\end{aligned}
$$

The nature of the temperature distribution inside the conductor is presented graphically in Figure1.

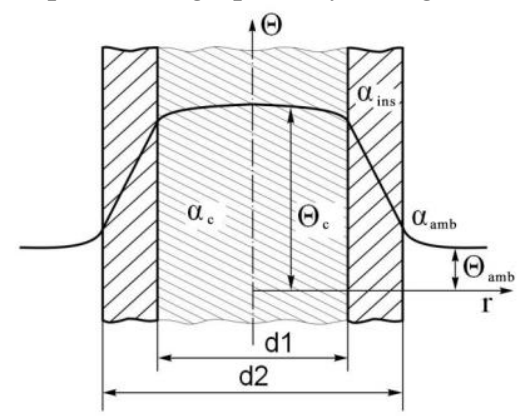

Figure 1. The temperature distribution in the conductor insulation.

Table 1. Conductor parameters

\begin{tabular}{|c|c|c|c|}
\hline Sectional area & $F$ & $\mathrm{~mm}^{2}$ & 240 \\
\hline $\begin{array}{c}\text { Chase resistance at } \\
300{ }^{\circ} \mathrm{K}\end{array}$ & $r_{300}$ & $\mathrm{Ohm} / \mathrm{m}$ & $2.8 \cdot 10^{-8}$ \\
\hline $\begin{array}{c}\text { The temperature of the } \\
\text { conductor }\end{array}$ & $T_{c}$ & ${ }^{\circ} \mathrm{C}$ & 90 \\
\hline $\begin{array}{c}\text { Temperature coefficient of } \\
\text { resistance of aluminum }\end{array}$ & $\alpha$ & ${ }^{\circ} \mathrm{C}^{-1}$ & 0.004 \\
\hline $\begin{array}{c}\text { Thermal conductivity of } \\
\text { wires }\end{array}$ & $\lambda$ & $\mathrm{W} /(\mathrm{m} \cdot \mathrm{K})$ & 209 \\
\hline $\begin{array}{c}\text { Thermal conductivity of } \\
\text { insulation }\end{array}$ & $\lambda_{\text {ins }}$ & $\mathrm{W} /(\mathrm{m} \cdot \mathrm{K})$ & 0.4 \\
\hline $\begin{array}{c}\text { The radius of the } \\
\text { conductor }\end{array}$ & $r_{1}$ & $\mathrm{~mm}$ & 8.74 \\
\hline $\begin{array}{c}\text { The radius of the } \\
\text { conductor assuming the } \\
\text { insulation }\end{array}$ & $r_{2}$ & $\mathrm{~mm}$ & 12 \\
\hline \begin{tabular}{c} 
Permissible current \\
\hline
\end{tabular} & $I$ & $\mathrm{~A}$ & 625 \\
\hline
\end{tabular}

\section{Simulation and results}

\subsection{Calculation of temperature and temperature gradient in the conductor}

One considers wire brand SAX-240 with XLPE insulation with the parameters given in Table 1 [13] loaded with the permissible current at an ambient temperature of $300 \mathrm{~K}$.

Heat in the conductor is

$$
\begin{aligned}
& q_{v}=\frac{1}{l \cdot F} I^{2} r \frac{l}{F}=\frac{I^{2} r_{300}\left(1+\alpha\left(\mathrm{T}_{c}-\mathrm{T}_{a m b}\right)\right)}{F^{2}} \\
& =\frac{625^{2} \cdot 2.8 \cdot 10^{-8}(1+0.004(273+90-300))}{\left(240 \cdot 10^{-6}\right)^{2}}=237739 \mathrm{~W} / \mathrm{m}^{3}
\end{aligned}
$$

The temperature difference and a temperature gradient in the conductor is defined with equations (10), (11)

$$
\begin{gathered}
\Delta \Theta=\frac{q_{v} r_{1}^{2}}{4 \lambda}=\frac{237739 \cdot 0.00874^{2}}{4 \cdot 209}=0.022{ }^{\circ} \mathrm{C} \\
\left(\frac{d \Theta}{d r}\right)_{a v}=\frac{\Delta \Theta}{r_{1}}=\frac{0.022}{0.00874}=2.52{ }^{\circ} \mathrm{C} / \mathrm{M}
\end{gathered}
$$

The calculation results on equations (10) and (11) show that all points of the temperature of the conductor section can be considered equal.

\subsection{Calculation of the change in temperature in the insulation excluding dielectric losses}

One determines the change in temperature according to equation (16) for a conductor cross section of $240 \mathrm{~mm}^{2}$, loaded to the permissible current of $625 \mathrm{~A}$ (Table 1).

$$
\begin{aligned}
& \Delta \Theta_{\text {ins }}=\frac{q_{v} r_{1}^{2}}{2 \lambda_{\text {ins }}} \ln \frac{r_{2}}{r_{1}} \\
& =\frac{237739 \cdot 0.00874^{2}}{2 \cdot 0.4} \ln \frac{0.012}{0.00874}=7.196^{\circ} \mathrm{C}
\end{aligned}
$$

\subsection{Calculation of the temperature change in the insulation based on the dielectric losses}

Assume clearly elevated levels of linear dielectric losses $\Delta p_{\text {ins }} \approx 10 \mathrm{~W} / \mathrm{km}$, which corresponds to $35 \mathrm{kV}$ cable with XLPE (Table 1). The value of $K_{1}$ is determined from the following equation:

$$
\Delta p_{\text {ins }}=\int_{r_{1}}^{r_{2}} q_{v, \text { ins }} 2 \pi r d r=2 \pi K_{1} \int_{r_{1}}^{r_{2}} \frac{d r}{r}=2 \pi K_{1} \ln \frac{r_{2}}{r_{1}}
$$

Under these conditions for the given conductor obtain 


$$
\begin{gathered}
K_{1}=\frac{\Delta p_{\text {ins }}}{2 \pi \ln \frac{r_{2}}{r_{1}}}=\frac{0.01}{2 \pi \ln \frac{0.012}{0.00874}} \\
=\frac{0.01}{2 \pi \cdot 0.316997}=0.0050207 \mathrm{~W} / \mathrm{m}
\end{gathered}
$$

$$
\begin{aligned}
& \Delta \Theta_{\text {ins }}=\frac{237739 \cdot 0.00874^{2}-2 \cdot 0.0050207 \ln 0.00874}{2 \cdot 0.4} \\
& \cdot \ln \frac{0.012}{0.00874}+\frac{0.0050207}{2 \cdot 0.4}\left(\ln ^{2} 0.012-\ln ^{2} 0.00874\right) \\
& =7.21482-0.01823=7.197 \text { 癈 }
\end{aligned}
$$

The temperature difference do not show changes from the obtained without the dielectric losses. Therefore, in the thermal calculations dielectric losses can be ignored.

Table 2. Conductor parameters

\begin{tabular}{|c|c|c|c|c|}
\hline $\begin{array}{c}\text { Chase resistance at } \\
20^{\circ} \mathrm{C}(\mathrm{Ohm} / \mathrm{m})\end{array}$ & $\begin{array}{c}\text { Temperature } \\
\text { coefficient of } \\
\text { resistance }\left({ }^{\circ} \mathrm{C}^{-1}\right)\end{array}$ & $\begin{array}{c}\text { The diameter of the } \\
\text { conductor }(\mathrm{m})\end{array}$ & $\begin{array}{c}\text { Degree of black } \\
\text { surface of the } \\
\text { conductor }\end{array}$ \\
\hline $6.74 \cdot 10^{-5}$ & 0.0039 & 0.0285 & 0.5 \\
capacity of the \\
conductor surface
\end{tabular}

Table 3. Practical cases considered

\begin{tabular}{|c|c|c|c|c|c|}
\hline Case & 1 & 2 & 3 & 4 & 5 \\
\hline Current $(\mathrm{A})$ & 600 & 650 & 600 & 970 & 600 \\
\hline $\begin{array}{c}\text { Ambient } \\
\text { temperature }\left({ }^{\circ} \mathrm{C}\right)\end{array}$ & 40 & 40 & 40 & 40 & 40 \\
\hline Wind speed $(\mathrm{m} / \mathrm{s})$ & 0,2 & 0,4 & 2 & 2 & 2 \\
\hline Wind direction $\left({ }^{\circ}\right)$ & 90 & 90 & 90 & 90 & 90 \\
\hline $\begin{array}{c}\text { The total solar } \\
\text { radiation }\left(\mathrm{W} / \mathrm{m}^{2)}\right.\end{array}$ & 980 & 980 & 980 & 980 & 980 \\
\hline Altitude $(\mathrm{m})$ & 1600 & 1600 & 1600 & 1600 & 300 \\
\hline
\end{tabular}

Table 4. The calculation results

\begin{tabular}{|c|c|c|c|c|c|c|}
\hline \multicolumn{2}{|c|}{ Case } & 1 & 2 & 3 & 4 & 5 \\
\hline \multirow{2}{*}{ CIGRE } & $\Theta_{\mathrm{c}}\left({ }^{\circ} \mathrm{C}\right)$ & 78.8 & 74 & 56.1 & 75 & 55.7 \\
\cline { 2 - 7 } & $\Delta \mathrm{P}(\mathrm{W} / \mathrm{m})$ & 29.36 & 33.95 & 27.37 & 75.85 & 27.33 \\
\hline \multirow{2}{*}{ IEEE } & $\Theta_{\mathrm{c}}\left({ }^{\circ} \mathrm{C}\right)$ & 78.2 & 73.6 & 54.6 & 72.3 & 53.3 \\
\cline { 2 - 7 } & $\Delta \mathrm{P}(\mathrm{W} / \mathrm{m})$ & 29.3 & 33.92 & 27.24 & 75.23 & 27.12 \\
\hline \multirow{3}{*}{ FEM } & $\Theta_{\mathrm{c}}\left({ }^{\circ} \mathrm{C}\right)$ & 80 & 76 & 55 & 73 & 54 \\
\cline { 2 - 7 } & $\Delta \mathrm{P}(\mathrm{W} / \mathrm{m})$ & 29.46 & 34.16 & 27.27 & 75.4 & 27.18 \\
\hline \multirow{2}{*}{$\begin{array}{c}\text { Proposed } \\
\text { model }\end{array}$} & $\Theta_{\mathrm{c}}\left({ }^{\circ} \mathrm{C}\right)$ & 77.5 & 76 & 54.4 & 73.1 & 53 \\
\cline { 2 - 7 } & $\Delta \mathrm{P}(\mathrm{W} / \mathrm{m})$ & 29.24 & 34.16 & 27.22 & 75.42 & 27.1 \\
\hline
\end{tabular}

\subsection{Assessment of the temperature rating accuracy and active power losses on the proposed model}

For the validation of the simulation according to Equations (1), (7) there were carried out numerical calculations of power losses and heat conductor of 429 brand-AL1/56-ST1. Initial data calculations are shown in Tables 2 and 3 [10], the results of calculations are shown in Tables 4 and 5. The results of calculations of the proposed model were compared to studies in [12] using the methods of IEEE [8], CIGRE [9], FEM [10].
Table 5. Errors in calculations of temperature and active power losses proposed model in comparison with CIGRE, IEEE, FEM methods

\begin{tabular}{|c|c|c|c|c|c|}
\hline Case & 1 & 2 & 3 & 4 & 5 \\
\hline$\Delta \Theta_{\text {CIGRE }}\left({ }^{\circ} \mathrm{C}\right)$ & 0.7 & 2.4 & 0.2 & 0.8 & 0.3 \\
\hline$\Delta \Theta_{\text {IEEE }}\left({ }^{\circ} \mathrm{C}\right)$ & 1.3 & 2 & 1.7 & 1.9 & 2.7 \\
\hline$\Delta \Theta_{F E M}\left({ }^{\circ} \mathrm{C}\right)$ & 2.5 & 0 & 0.6 & 0.1 & 1 \\
\hline$\delta\left(\Delta P_{\text {CIGRE }}\right)(\%)$ & 0.21 & 0.71 & 0.07 & 0.25 & 0.07 \\
\hline$\delta\left(\Delta P_{\text {IEEE }}\right)(\%)$ & 0.41 & 0.62 & 0.55 & 0.57 & 0.84 \\
\hline$\delta\left(\Delta P_{\text {FEM }}\right)(\%)$ & 0.75 & 0 & 0.18 & 0.03 & 0.29 \\
\hline
\end{tabular}

The calculation of direct and diffuse components of solar radiation for the proposed model was carried out determining the highlands, for which we can assume approximately the ratio of forward and reverse components of solar radiation 1/10. Determining all this we take the value of the direct component $q_{\text {s.dir }}=900$ $\mathrm{W} / \mathrm{m}^{2}$, and reverse $q_{\text {s.dif }}=80 \mathrm{~W} / \mathrm{m}^{2}$. The shading coefficient is adopted $k_{s h}=0.6$, and the angle between the axis of the conductor and the direction of the solar rays $\varphi_{s}$ $=\pi / 4$. At low wind speeds $(0.2$ and $0.4 \mathrm{~m} / \mathrm{s})$ the calculation is performed with the model proposed determining the natural convection, and with a wind speed of $2 \mathrm{~m} / \mathrm{s}$ - determining the forced convection.

Active power losses is calculated according to equation (6).

To ease the analysis use the notation as shown in equations (23-28)

$$
\begin{gathered}
\Delta \Theta_{C I G R E}=\left|\Theta_{c}-\Theta_{C I G R E}^{c}\right| \\
\Delta \Theta_{I E E E}=\left|\Theta_{c}-\Theta_{I E E E}^{c}\right| \\
\Delta \Theta_{F E M}=\left|\Theta_{c}-\Theta_{F E M}^{c}\right|
\end{gathered}
$$




$$
\begin{gathered}
\delta\left(\Delta P_{\text {IEEE }}\right)=\left|\frac{\Delta P-\Delta P_{\text {IEEE }}}{\Delta P_{\text {IEEE }}}\right| 100 \% \\
\delta\left(\Delta P_{\text {CIGRE }}\right)=\left|\frac{\Delta P-\Delta P_{\text {CIGRE }}}{\Delta P_{\text {CIGRE }}}\right| 100 \% \\
\delta\left(\Delta P_{F E M}\right)=\left|\frac{\Delta P-\Delta P_{F E M}}{\Delta P_{F E M}}\right| 100 \%
\end{gathered}
$$

where $\Delta \Theta_{C I G R E}, \Delta \Theta_{\text {IEEE }}, \Delta \Theta_{F E M}$ are absolute error of calculation proposed method by the temperature of the conductor with respect to the standards of CIGRE, IEEE, FEM; $\Theta_{c}$ is the temperature of the conductor calculated with the proposed method; $\Theta_{\text {IEEE }}^{c}, \Theta_{C I G R E}^{c}, \Theta_{F E M}^{c}$ are the temperature of the conductor calculated with the IEEE, CIGRE, FEM, respectively; $\delta\left(\Delta P_{I E E E}\right) \quad$, $\delta\left(\Delta P_{\text {CIGRE }}\right), \delta\left(\Delta P_{F E M}\right)$ are the relative errors of calculation of power losses with the proposed method in comparison with the calculations of the losses of power with the standards of IEEE, CIGRE, FEM, respectively; $\Delta P$ is active power losses calculated with the proposed method; $\Delta P_{\text {IEEE }}, \Delta P_{C I G R E}, \Delta P_{F E M}$ are active power losses calculated using IEEE, CIGRE, FEM, respectively.

\section{Conclusion}

Table 5 shows that the absolute error in the calculation of temperature conductor on the proposed model does not exceed $2.7^{\circ} \mathrm{C}$, compared with IEEE and CIGRE, FEM. The relative error in the calculation of active power losses is less than $1 \%$. The maximum deviation of the temperature of IEEE and CIGRE corresponding to the wind speed is $\mathrm{v}=0.4 \mathrm{~m} / \mathrm{s}$. Perhaps this fact is due to the fact that the calculations for the proposed model for $\mathrm{v}=0.4 \mathrm{~m} / \mathrm{s}$ were carried out on the assumption of natural convection. However, calculations made for $\mathrm{v}=0.4 \mathrm{~m} / \mathrm{s}$ with the Finite Element Method gives the temperature $76{ }^{\circ} \mathrm{C}$, which coincides with the result obtained with the proposed model. Calculations were carried out for the bare overhead conductor. Indirectly, it confirms the validity of the proposed theory, as the equation for the bare overhead conductor is a special case of conductors with insulation at $\lambda_{\text {ins }}=0$.

\section{Acknowledgment}

The paper was prepared in Omsk State Technical University with financial support from Ministry of Education and Science in the framework of the agreement № 14.577.21.0097 on August 22, 2014. A unique identifier of applied research RFMEFI57714X 0097.

\section{References}

1. W.Q. Sun, Y. Zhang, C.M. Wang, and P. Song, IET Generat., Transmiss., Distrib., vol. 7, no. 2, pp. 130137,2013

2. J. Heckenbergerova, P. Musilek, and K. Filimonenkov, in Proc. IEEE Power Energy Soc. Gen. Meeting, pp. 1-8, 2011.

3. H. T. Yip, C. An, J.G. Lloyd, P. Taylor, A. Michiorri, S. Jupe, M. Barlett, 10th IET International Conference on, IET, pp. 1-5, 2010.

4. D. M. Greenwood, J.P. Gentle, K.S. Myers, P.J. Davison, I.J. West, J.W. Bush, G.L. Ingram, and M.C. Troffaes, IEEE Trans. Power Del., vol. 29, no. 4, pp. 1849-1858, 2014.

5. T.O. Seppa, IEEE Power Eng. Soc.Winter Meeting, vol. 2, pp. 1208-1211, 2002.

6. I. Albizu, E. Fernandez, P. Eguia, E. Torres, and A.J. Mazón, IEEE Trans. Power Del., vol. 28, no. 1, pp. 3-10, 2013.

7. V.T. Morgan, Electric power systems research, vol. 6, no.4, pp. 287-300, 1983.

8. IEEE, "Standard for calculating the current temperature of bare overhead conductors, Std 738," 2006.

9. Cigr'e Working Group 22.12, "Thermal behaviour of overhead conductors," Cigr'e Brochure 207, Aug. 2002.

10. F.A. Gomez, J. M. Garcia De Maria, D. Garcia Puertas, A. Bairi, R. Granizo Arrabe, Proceedings of the 10th WSEAS international conference on communications, electrical \& computer engineering, and 9th WSEAS international conference on Applied electromagnetics, wireless and optical communications. World Scientific and Engineering Academy and Society, pp. 149-153, 2011.

11. A. In. Bulgarian, Thermodynamics and Heat Transfer, Ripol Klassik, 1975, p. 495.

12. K.S.Demirchian, L.R. Neumann, N.V. Korovkin, V.L. Chechurin, Theoretical Foundations of Electrical Engineering: SPb: Peter, vol. 3, p. 377, 2006.

13. V.G. Gerasimov, Electrical Engineering Handbook, MEI Publishing, vol. 1, p. 440, 1995 